\title{
An Evaluation Study of a Nature Based Rehabilitation in Sweden for Patients with Exhaustion Disorder
}

\author{
Gärd Holmqvist* (), Cristina Lundqvist-Persson \\ Skaraborg Institute for Research and Development, Regionens Hus, Skövde, Sweden \\ Email: *gard.holmqvist@telia.com, cristina.lundqvist-p@vgregion.se
}

How to cite this paper: Holmqvist, G. and Lundqvist-Persson, C. (2021) An Evaluation Study of a Nature Based Rehabilitation in Sweden for Patients with Exhaustion Disorder. Health, 13, 934-954.

https://doi.org/10.4236/health.2021.139072

Received: August 10, 2021

Accepted: September 7, 2021

Published: September 10, 2021

Copyright $\odot 2021$ by author(s) and Scientific Research Publishing Inc. This work is licensed under the Creative Commons Attribution International License (CC BY 4.0).

http://creativecommons.org/licenses/by/4.0/

\section{(c) (i) Open Access}

\begin{abstract}
The aim of this study was to evaluate a Nature Based Rehabilitation (NBR) for a group of patients with Exhaustion Disorder (ED) in the southwest Sweden. A multidisciplinary team consisting of an occupational therapist, a physiotherapist, a medical doctor practising symbolic drama and a nurse with gardening experience provided NBR in an agricultural environment. Patients were offered 14 weeks of rehabilitation in a group of eight persons, three mornings per week. Seventeen patients participated in the study and 15 completed the study. A semi-structured interview was conducted at the beginning of the rehabilitation and at the end and a follow-up interview by telephone was done one year after completion of the rehabilitation. The interviews were recorded and transcribed. Assessment scales used included: Stress and Crisis Inventory (SCI-93), Coping Resources Inventory (CRI) and Visual Analogue Scale (VAS). Weekly notes from the staff members were reviewed and compared with the patient's own experience. The interviews and the staff notes were analysed with semantic thematic analysis. Result showed that this kind of NBR with a multidisciplinary team promotes improved health and improved quality of life for patients with ED and may thus constitute a good alternative to treatment, provided the ED has not become chronic.
\end{abstract}

\section{Keywords}

Burn Out Syndrome, Exhaustion Disorder, Stress Disorder, Nature Based Rehabilitation

\section{Introduction}

The World Health Organization (WHO) classifies burn-out syndrome as an occupational phenomenon, not as a medical condition. "Burn-out is a syndrome 
conceptualized as resulting from chronic workplace stress that has not been successfully managed" [1]. This differs from the Swedish understanding of burn-out as a condition caused by a prolonged stress load and by several different stress factors over the course of at least 6 months. To date, Sweden is the only country to have introduced a specific diagnosis, Exhaustion Disorder (ED) [2]. This study has been conducted in a Swedish context and with Swedish diagnostic criteria, thus the term Exhaustion Disorder, ED, will be used.

ED is characterized by extreme fatigue that is not alleviated by rest, in addition to sleep disorders and increased sensory sensitivity [3]. Other known symptoms are gastrointestinal disorders, pain, cognitive impairment, mood swings, depressed mood, anxiety and marked feelings of shame. Comorbidity is frequently present, for example, Irritable Bowel Syndrome (IBS), Attention Deficit Hyperactivity Disorder (ADHD), depression and anxiety. Factors such as personality and early trauma can also be a factor [4]. The affected patients are frequently perceived as ambitious, strong and tenacious both by themselves and people around them. In many cases, their self-esteem is deemed to be related to their performance, which means that they value themselves in terms of how their achievements are viewed by others [5].

There is still no evidence-based treatment or rehabilitation available for patients suffering from ED [6]. In most cases, measures such as sick-leave, rest and medication are not sufficient to enable patients to regain health and vitality. But a recent study about a model in primary care, with a complementary medicine program integrated with traditional medicine, showed effect on people with stress-related fatigue disorder [7]. Furthermore, not only individually adapted rehabilitation interventions and a modified life situation are required, but also a demand on well-functioning co-operation between different care units, the Social Insurance Agency and labour market actors [8].

\subsection{Nature Based Rehabilitation}

In Sweden, Nature Based Rehabilitation (NBR) is a non-standardized form of Green Care that targets patients with ED. Some of the NBR activities are led by a multidisciplinary team, usually comprising an occupational therapist, a physiotherapist, a psychologist or other professional with psychotherapeutic competence, as well as staff with competence in the area of nature and gardening [6]. The advantage of a multidisciplinary team is that it prevents the splitting of the patient's multi-facetted problems. NBR often takes place in a group and studies have demonstrated that the strength of group treatment lies in encountering like-minded people as well as the experience of not being alone in having a dysfunctional life situation [9].

NBR with a multidisciplinary team for patients with ED has been studied in Sweden before [10] [11] [12] [13] and despite these studies have reported positive results they do not constitute a sufficient basis for NBR to be judged as evidence-based. Further research is needed. 


\subsection{Theoretical Background}

The Attention Restoration Theory (ART) describes two different forms of human attention; a will-controlled or directed system defined as voluntary attention, linked to the ability to concentrate and to screen out irrelevant stimuli, and a non-will-controlled system defined as involuntary attention, also known as fascination [14]. Voluntary attention requires energy and recovery, which can be facilitated in so-called restorative environments such as nature. The nature contributes to recovery because the human being is used to spending time in nature and reacts positively to natural environments [15]. The biophilia hypothesis, the love of life, is another theory built on the view that the human being has a genetic propensity to appreciate spending time in nature and like living creatures as well as the fact that animals exert a positive influence on well-being [16]. The biophilia hypothesis has had a great influence on the Green Care but it also has been criticized for overestimating the evolutionary psychology perspective [17]. Research has also shown the opposite, that love to life is not an innate property based on the evolution, which does not mean that people cannot appreciate and recover in the nature. Another explanation why nature can be conducive to alleviating stress is nature's own self-repeating patterns, so called fractals [18]. Natural, self-repeating patterns in, for example, trees and ferns stimulate the human brain, which sustains curiosity and alertness at an exact level that is adequate.

In Sweden, sick leave due to stress and related mental ill health, has increased since 2009 and ED has become a great public health problem, primarily in women aged 30 - 49 years [19]. In view of the fact that the number of individuals affected by ED is on the increase, that no evidence-based treatment is currently available and that studies have demonstrated several good results of NBR with multidisciplinary teams, there is every reason to deepen the knowledge of NBR for patients with ED.

\section{Aim}

The aim was to evaluate an intervention with Nature Based Rehabilitation (NBR) for a group of patients with Exhaustion Disorder (ED).

\section{Research questions}

- Are the patients' ED symptoms reduced after completion of NBR?

- Do the patients experience that they have undergone a change and, if so, in what way?

- Which components of NBR were important in any change, improved health or increased well-being?

- Are the patients ready to return to their workplace, another work or structured activity such as education?

\section{Materials and Methods}

\subsection{Ethical}

Ethical principles have been followed in accordance to the Helsinki Declaration 
World Medical Association (WMA), [20] and The Swedish Research Council's national guidelines [21]. The study has been approved by The Ethical Review Board [22] in December 2014 (Dnr: 80416).

\subsection{Participants}

The study included individuals on sick leave who had been referred to NBR by a care centre or occupational health care. The diagnosis ED was established by referring medical doctor and confirmed in an assessment interview carried out by a team member at the NBR before joining the rehabilitation.

The patients were offered 14 weeks of rehabilitation in a group of eight persons, three mornings (4 hours) per week. In the period 2017-2018, 24 patients from three groups were invited to participate in the study. Seventeen patients, 15 women and 2 men, agreed to participate. One participant stopped during the rehabilitation and one could not be reached for the follow-up interview one year after the rehabilitation. However, data collected on them have been included in the study. Why some patients chose not to participate in the study have for ethical reasons not been investigated.

The group of participation patients was heterogeneous in terms of life situation, personality, underlying traumatic factors and comorbidity. Their ages varied between 32 and 63 years, with a median age of 43 years (Table 1). All of them had at least secondary level of vocational education. Half of them worked

Table 1. The participants background.

\begin{tabular}{|c|c|c|c|c|}
\hline Patient & Sex & Age & Work & Life situation \\
\hline 1 & Woman & 56 & Laboratory assistant & Family \\
\hline 2 & Woman & 41 & Own business & Family \\
\hline 3 & Woman & 37 & Factory worker & Family \\
\hline 4 & Man & 60 & Teacher & Family \\
\hline 5 & Woman & 32 & Nurse & Single \\
\hline 6 & Woman & 36 & Administration & Family \\
\hline 7 & Woman & 55 & Assistant nurse & Single \\
\hline 8 & Woman & 52 & Own business & Family \\
\hline 9 & Woman & 36 & Employment services & Single \\
\hline 10 & Woman & 63 & Nurse & Single \\
\hline 11 & Woman & 36 & Assistant nurse & Family \\
\hline 12 & Man & 48 & IT workers & Family \\
\hline 13 & Woman & 34 & Teacher & Single \\
\hline 14 & Drop out & & & \\
\hline 15 & Woman & 50 & Teacher & Family \\
\hline 16 & Woman & 44 & Biologist & Family \\
\hline 17 & Woman & 38 & Store manager & Family \\
\hline
\end{tabular}


within the care sector or in schools, while others were self-employed, managers or worked in state agencies. Several patients had stable family situations with children but there were also some who were single with or without children. All participants had a well-ordered social situation but some stated that their financial situation had deteriorated due to sick leave.

The majority of the participants were still in permanent employment and had tried to return to work between periods of sick leave, in some cases several times. When asked about sick leave due to $\mathrm{ED}$, the patients were not able to state the exact length of sick leave. The symptoms often came on insidiously and was sometimes triggered by a trauma or a somatic disease. Some participants had experienced a reduction in work capacity during a reorganization in the workplace. Others had opposed sick leave despite the need for it. It was also not uncommon for sick leave to be replaced by work training. At the start of NBR, patients reported periods of sick leave ranging from a few months to several periods of varying length over ten years and a varying extent from $25 \%$ to $100 \%$. At the time of the study, all participants were $100 \%$ on sick leave in order to participate fully in the rehabilitation.

\subsection{Intervention}

A multidisciplinary team comprising of an occupational therapist, a physiotherapist, a medical doctor who was also a practicing symbol drama therapist and a nurse with gardening experience provided NBR at a farm with a garden and a green house in an agricultural environment. The design and content of this model of NBR had previously been developed by the team and tested. It had been based on other similar activities where research has been conducted [11]. The activities were structured as regular morning routines consisting of relaxation, a walk in the open agricultural landscape and a coffee break. This was followed by activities such as body awareness therapy, symbolic drama practice, handicraft and gardening.

\subsection{Evaluation Methods}

A qualitative design with semi-structured interviews with follow-up questions were chosen to evaluate patients' experience of development and change after treatment with NUR [23] [24]. Since we were interested in detailed individual results a focus group discussion was not relevant. Assessment scales were used with the intention to complement the interviews. Staff notes on the patient's health status, progress and development as well as unexpected events were reviewed and compared with the patient's own experience.

\subsection{Interviews}

The semi-structured interviews were carried out on three occasions: at the start of rehabilitation with 17 participants, after 14 weeks of rehabilitation with 16 participants. One year after completion of the NBR, 15 participants took part in 
a telephone interview.

An interview guide was developed in relation to the research questions. For example, was one of the issues about the experience of quality of life, another was about events and developments until the patient felt ill. The emphasis was on the patient's own story and follow-up questions were asked, if necessary, in case of further need for clarification, the patient was encouraged to illustrate with concrete examples [25].

The follow up interview after finishing the rehabilitation, focused on whether the participants had experienced any change in quality of life, disease status, what thoughts and feelings they had about themselves and the rehabilitation, if they had had any surprising experiences and whether they had learnt something new. The telephone interview 12 months after the completion of the rehabilitation concerned the past year, care contacts, medication, work and other activities, lifestyle changes, social contacts and current quality of life.

All interviews were held by the first author $(\mathrm{GH})$, experienced clinician and interviewer. The interviews lasted from 15 to 45 minutes. They were recorded, transcribed and analysed with a semantic thematic analysis which means that the themes are identified within the explicit meaning of the data and the researcher is not looking for anything beyond the patient's statement [26]. The staff's weekly notes also were analysed with thematic analysis.

\subsection{Assessment Scales}

The assessment scales were chosen with great care. With respect to the patients' concentrating difficulties by reading and writing it was important to use as few scales as possible, estimated as meaningful and necessary. The scales were aimed to clarify questions of change assumed as difficult for the patient to describe due to symptoms such as memory problems and fragility. The scales were about the patient's being over time, coping ability, stress symptoms and resources for rehabilitation towards work or other activity. Quality of life scales were considered but not included. As patients sustained for a long time on the theme in the interviews and that several of them had no idea what quality of life could be for them the issue was perceived as saturated. The results of the scales were communicated to patients in paper form and they provided an appreciated basis in the interviews.

Stress and Crisis Inventory, (SCI-93) is a self-rating scale that consists of two parts in order to examine the reaction to stress and crises in addition to assessing the individual's occupational resources [27]. One part is assessing autonomous dysfunction encompassing 35 statements about bodily complaints deemed a hindrance in everyday life. The degree of each complaint is assessed and the total number of points indicates the current stress level on a scale from $0-140$. The higher the level of stress symptoms, the harder it is for the patient to return to work. To evaluate if autonomous stress symptoms change over time the assessing was implemented before each interview, e.g., three times. The other part is a questionnaire comprising five areas: 1) the occurrence of burdensome events 
in the patient's life, 2) disease, 3) perspective on one's own health, 4) function and ability, 5) return to work or the need for permanent sickness benefit. If the patient states that problems exist in a certain area, the extent to which they constitute a hindrance in everyday life and affect their intellectual and emotional life is also rated. In addition, their reorientation ability is rated. This part was used once before the second interview. The aim was to support the patient's own experience of work ability conquered by the rehabilitation with NBR.

Coping Resources Inventory, (CRI) focuses on indicating the individual's resources in stress situations [28]. The test contains five scales; cognitive, social, emotional, spiritual and physical. The scales mirror different aspects of the ability to face, cope with and recover from stress. With the aim to evaluate if coping resources increased through the rehabilitation with NBR the test was used twice, before the first and the second interview.

Visual Analogue Scale, (VAS) is a 15-point vertical VAS-scale without numbers was designed to rate the actual state of health, where zero denotes the worst possible and 15 the best possible state of health. The assessment was performed throughout the whole rehabilitation. At the start and end of each week the patient put a cross on the line, which was then measured using a ruler. The aim was to evaluate the patient's general state of health over time.

Examination of Staff Members Weekly Notes. These weekly notes with a summary of the patient's state of health as well as any developments or unexpected events were analysed with thematic analysis [26].

\section{Results}

Sixteen patients completed the first 14 weeks rehabilitation, which is 42 days. Three of them with more extensive rehabilitation needs were offered an additional 14 weeks rehabilitation (5, 9 and 11). Towards the end of the programme, the first and the second group were offered an extension of 1 day per week for eight weeks. Eleven patients $(2-12)$ participated in this extended programme. The extended program was not available to the last three people $(15-17)$ due to the end of the project (Table 2).

\subsection{Interview Results}

The semantic thematic analysis [26] resulted in five themes: quality of life, change process, the importance of the group, work or other activities, new knowledge and staff members perceptions of the changes in the patients.

In order to make the patients process of change visible, the results of the three interviews, (before NBR, after the NBR and one year later) are presented coherent under each theme. This is to increase the understanding that a stable change occurs continuously over a long period of time.

\section{Quality of life}

In the first interview some participants noted that they had never reflected on what quality of life meant to them personally. These patients were instead pre- 
Table 2. The extent of rehabilitation in number of days.

\begin{tabular}{|c|c|c|c|c|}
\hline Patient & $\begin{array}{l}\text { The first period } \\
\text { of } 42 \text { days }\end{array}$ & $\begin{array}{l}\text { The second } \\
\text { period of } 42 \text { days }\end{array}$ & $\begin{array}{c}\text { Extended } \\
\text { Programme of } 8 \text { days }\end{array}$ & $\begin{array}{c}\text { Total number } \\
\text { of days }\end{array}$ \\
\hline 1 & $\mathrm{X}$ & & & 42 \\
\hline 2 & $\mathrm{X}$ & & $\mathrm{X}$ & 50 \\
\hline 3 & $\mathrm{X}$ & & $\mathrm{X}$ & 50 \\
\hline 4 & $\mathrm{X}$ & & $\mathrm{X}$ & 50 \\
\hline 5 & $\mathrm{X}$ & $\mathrm{X}$ & $\mathrm{X}$ & 92 \\
\hline 6 & $\mathrm{X}$ & & $\mathrm{X}$ & 50 \\
\hline 7 & $\mathrm{X}$ & & $\mathrm{X}$ & 50 \\
\hline 8 & $\mathrm{X}$ & & $\mathrm{X}$ & 50 \\
\hline 9 & $\mathrm{X}$ & $\mathrm{X}$ & $\mathrm{X}$ & 92 \\
\hline 10 & $\mathrm{X}$ & & $\mathrm{X}$ & 50 \\
\hline 11 & $\mathrm{X}$ & $\mathrm{X}$ & $\mathrm{X}$ & 92 \\
\hline 12 & $\mathrm{X}$ & & $\mathrm{X}$ & 50 \\
\hline 13 & $\mathrm{X}$ & Only 12 days & & 54 \\
\hline 14 & Drop out & & & \\
\hline 15 & $\mathrm{X}$ & & n.a.* & 42 \\
\hline 16 & $\mathrm{X}$ & & n.a.* & 42 \\
\hline 17 & $\mathrm{X}$ & & n.a.* & 42 \\
\hline
\end{tabular}

${ }^{*}$ n.a. $=$ not available.

occupied with ensuring that those around them had a good quality of life. One woman reacted to the question with surprise and replied: "This is really interesting actually, the question what is quality of life for you, I cannot answer but at the same time I know what quality of life is for others'. Another participant realized that its definition of quality of life was a crucial reason for ED:

"My identity and my motivation to exist was to consume myself at work [...] I sacrificed everything for the job simply and my identity and motivation to exist was to consume myself at work".

However, the most participants knew what quality of life was for them, e.g., ability to deal with family and daily tasks or strength to cope with a job, but also to feel calm and enjoy life. The loss of life quality could depend on personal characteristics as overestimating their work value or of perfectionism. Reduced or lost quality of life could also be due to changing living conditions as having become a parent, family member's illness and a great deal of distress.

In the second interview, some patients experienced a slightly improved health state and quality of life. This could include maintaining the morning routines that they had learned during the rehabilitation, prioritizing enjoyable activities or acquired a long-awaited pet: " $P$ ve kept the routine from green care, $P m$ very strict about taking a walk, and relaxing, and get a cracker sandwich". The feeling 
of hope for the future had change in diverse ways, for some participants it has been raised, for others increased.

One year later, all participants experienced improved quality of life although to varying degrees. The majority stated that the most important was to become more attentive to their own needs and get a balance between own and others' needs, engaging in activities that they knew made them feel good and minimizing activities that affected them negatively, e.g., "I am not so much social any longer". Several of the participants had made important decisions that had altered their preconditions for the future, such as changed residence, got a new job, reduced the number of social contacts and ended destructive contacts: " $I$ have limited my circle of friends to those I feel good about". A number of the patients had stopped struggling to regain their full work capacity. Instead, they focused on trying to attain a better quality of life by working less, applying for sick leave or a retirement pension.

Improved quality of life was also associated with further assessments within somatic or psychiatric care and resulted in adequate treatment for diseases such as fibromyalgia, IBS and depression: "Now I have been to the psychiatry and I have been examined there [...] no, he did not think I was depressed, he confirmed my $E D^{\prime \prime}$. While some had started medication, others had opted to end medication, for example antidepressants. One participant had started psychotherapy and several participants had resumed contact with their previous psychotherapist or physiotherapist. Others continued pursuing activities to improve their well-being such as meditation, yoga or training in a gym.

\section{Change process}

After the rehabilitation, the majority of patients stated that there were signs of reduced bodily symptoms, although the symptoms of exhaustion could still dominate their life. The absence of demands during rehabilitation made several patients acknowledging their need for recovery: "I have gained my own time". Some experienced that their state of health was better and others that it varied: " $I$ sleep better now, even if I do not sleep welr'. All participants who had gained new insights had an experience of change. This change mainly involved greater acceptance of their present life situation, learning to take one day at a time and trying to find a balance between activity and rest. Several had attained greater hope for the future and did not feel as despairing as previously: "P ve started to feel a little more hope [...] somehow, I feel like I finally managed to start having a little more positive thoughts, both about myself and about the future".

At the follow-up one year later, all 15 patients interviewed stated that the rehabilitation had become the start of something new: "It was the major turning point in this disease process". They had been stimulated into reflecting more about themselves and had gained greater access to both positive and negative feelings. The absence of demands provided the opportunity to rest and recovery, while the lack of stress gave them space to reflect on the meaning of suffering from ED: "At the beginning I thought this is nothing for me, I don't have ED and I do not belong here [...] then I understood that ED was about me". Greater 
self-knowledge was seen as a pleasant surprise. Furthermore, self-empathy had increased, which meant acceptance of the human disposition, the view that difficulties are part of human existence as well as a quiet acceptance of all kinds of emotions and thoughts. For some participants, the ED symptoms had continued to decrease during the year after the rehabilitation, while for others their tolerance of the symptoms had increased and they now tried to learn to live with them: "I try to think about the breathing, I have understood that it is important". However, for someone the rehabilitation was so exhausting that the bodily stress symptoms increased.

\section{The importance of the group}

During the first interview, the participants' expectations of the rehabilitation were more or less vague wishes to receive help. Fourteen weeks later, almost all expressed that the group and its participants had been a very positive surprise: "The togetherness of the group is great, I guess I didn't really expect that". Being together with like-minded people who understood, without the need for words and without judging, was a new experience. Sharing their experience of exhaustion with others in the same situation contributed to greater acceptance of oneself and reduced their feelings of guilt and shame. However, in some cases the positive experiences were not related to the whole group, but to certain individual participants. These persons could experience being surrounded by the entire group as noisy, loud and tiring. They therefore took advantage of the opportunity for privacy with a like-minded participant.

One year after the rehabilitation, all patients agreed that the group and its members was especially valuable: "We've had a really good group where we' ve been very open and that has meant that you have gained a lot of understanding, for your own situation". The security they experienced in the group allowed them to talk openly about difficulties they had not even dared tell their closest family members. Recognizing oneself in another patient's story had helped them see themselves from the outside and together they had been able to view their behaviour with humour: "I started recognizing their stuff. When they told I thought $P$ ve heard that before an I recognise that?' For some patients, this contributed to reduced shame and self-criticism, improved self-image and enhanced self-esteem. Those who took part in the extended programme comprising eight weeks, underlined its importance in terms of facilitating their return to everyday life without the company and support of the rehabilitation group.

\section{Work or other activities}

After 14 weeks of rehabilitation, the majority of patients had realized that returning to work would take time but they still had long-term plans to return to some kind of work at least part-time. Several of them were involved in ongoing planning with support from the Social Insurance Agency, which they considered extremely valuable: "I think that since it's going in the right direction, I Il be able to work part-time within a few years". A number of them had been dismissed during the rehabilitation period and were now unemployed. 
One year after the rehabilitation, none of the participants had returned to full-time work. On the other hand, almost all of them were in some way in the process of returning to work, in most case in cooperation with the Social Insurance Agency or the Public Employment Service. The interventions varied greatly. For example, for one participant, the work was adapted to her health status, another participant had obtained trainee posts aimed at leading to education and employment and one participant felt obliged to return to full-time job due to the risk of becoming unemployed: "There was a termination at my job, then I became re-employed so I do not dare to be sick leave even if I really do not have the strength".

One younger participant was proposed to apply for a permanent sick leave by Social Insurance Office, which was considered an impossible alternative. On own initiative, this participant obtained a suitable part-time job paid at an hourly rate. Patients who did not feel ready for work training were still on sick leave but took part in some form of therapy including psychotherapy, art therapy, physiotherapy or additional rehabilitation activities focused on return to work. After several periods of failed work training, one patient who had only a few years left in working life chose to retire: "I made a mature decision now that I would retire, because I tried to fight and I tried to work out and discovered that I have very little, very little left. By the time $P$ ve worked three hours, I $m$ was totally done, so that's what happened".

\section{New knowledge}

At the start of rehabilitation with NBR, many of the patients had struggled to understand why they had performed beyond their ability over a long period of time. They felt guilty and ashamed. The feeling of complete worthlessness and having lost their human dignity triggered great mental pain and a significant identity crisis: "To go in to the wall... it's a very terrifying event".

One year after the rehabilitation, the patients had learnt to know themselves and their own limits better, how to be economical with their energy, how to allocate time for rest when planning activities and how to take account of and respect their current condition. They had acquired greater understanding of their situation and realized the impact of their life story an important realization was the fact that a performance-based self-image leads to high demands on oneself, the wish to please and never say "no", taking great responsibility for others but not for oneself and the belief that you are interchangeable: " $P m$ a little more resolute saying no to things now".

For almost all of the participants, body awareness and learning about stress symptoms gave new insights. When they realized that a range of different somatic symptoms could be signs of stress, their fear of suffering from a serious somatic disease was reduced: "It overflowed, in the body so I understood that this is stress". Above all, this led to increased attention to and understanding of their own reaction patterns, which in turn led to behaviour change or altering the situation that triggered the stress. 
Others expressed surprise that symbolic drama was such a powerful therapy, stating that it had provided them with deeper insights about themselves and that their ED was related to childhood experiences and previous traumas. It became clear that previous events still affected them: "I have realized that much of my exhaustion is due to emotional stress that I have lived with for a very long time, since adolescence [...] I have to deal with myself, once and for alP'. Some perceived that staff members' knowledge and care were greater than anticipated and described: "to be seen" as very valuable. A number of participants underlined that gardening and handicraft had inspired and reawakened earlier interests and skills. The activities made it possible to feel stimulated on an experience level, in several cases to feel creative and experience the joy of being able to do things.

\section{Staff members' perceptions of the changes in the patients}

There was agreement between the staff members' daily notes and the patient interviews. The notes revealed detailed knowledge of each patient's difficulties. There were empathetic notes about the patients' despair at having lost certain functions, their tendency to overestimate as well as underestimate their abilities, how they wrestled with the necessity to make difficult decisions, their lack of routines in everyday life, their poor dietary habits and their existential anxiety. Efforts were made to foster individual development and change by identifying and addressing the challenges and needs of individuals, in addition to utilizing the resources of the group and the environment. The team members actively supported reorientation and were present at meetings with the Social Insurance Office, constituting an essential support for the patient in a stressful situation. Here, they contributed their assessment of the patient's resources in order to find a reasonable level at which to continue planning.

\subsection{Rating Scales Result}

The assessment scales did not show any significant personal changes in the participants, but you could see a trend of changes. However, in the interviews the participants clearly described an experience of change in attitude to their symptoms and expressed an understanding of the relationship between the symptoms and stress. The results of the scales were compiled at group level and the results meant that a further statistical analysis would not add anything new.

The Visual Analogue Scales ( VAS)

According to the VAS scale, the perceived state of health of all participants fluctuated between the worst possible and the best possible (Figure 1). The patients considered that the results of the rating were affected by the fact that it was performed at the beginning and at the end of the week. Some were more tired on Monday mornings and more alert at the end of the week, while others reported the opposite situation. Nevertheless, the results revealed great variations in perceived state of health, distributed between 0 and 14.7 on the 15 -point scale. Some exhibited very sharp fluctuations, an example being 0.3 - 12.6 (Figure 1), while the fluctuations of other participants were more gradual. Only one patient 


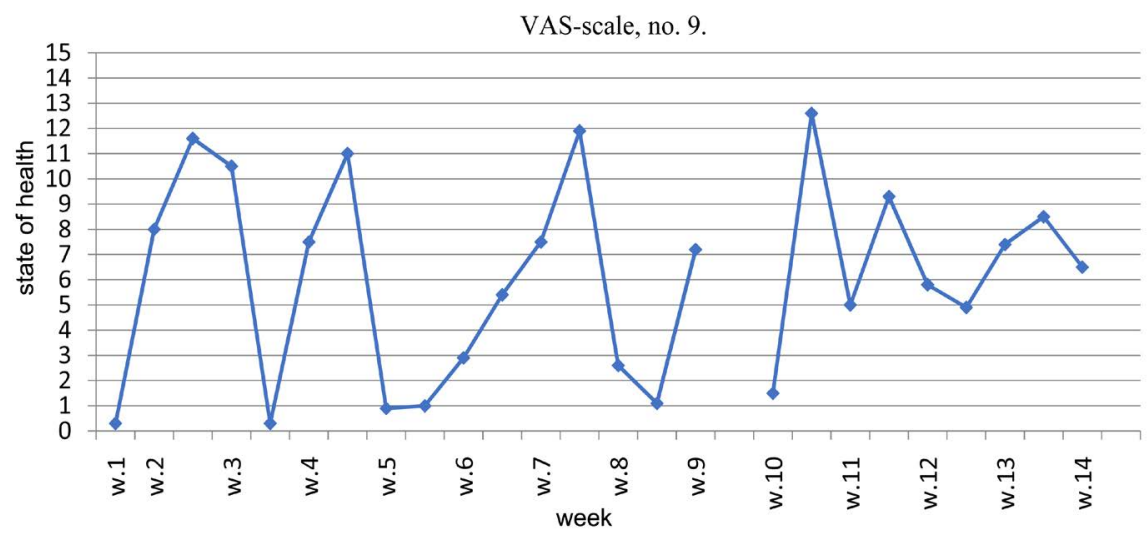

Figure 1. An example of the strong fluctuations during a period of 14 weeks. Each week is marked with two points. The patient was absent at week nine.

exhibited a constantly ascending curve with minor fluctuations ranging from 4.7 11.7. One year later, some patients perceived that their state of health had stabilized, while others reported continual strong fluctuations.

\section{The SCI-93, autonomous dysfunction, rated by 16 patients}

The rating of autonomous dysfunction took place before the start of rehabilitation as well as after 14- and 28-weeks rehabilitation (Figure 2). At the initial rating, none of the participants were in the group with a normal stress level (0 $25 \mathrm{p})$ nor in the group with mild symptoms $(26-50 \mathrm{p})$. They all exhibited a higher level of dysfunction (51 - 75 p, $76-100$ p, $101-140$ p). This indicates stress level symptoms that lead to different degrees of difficulty in terms of rehabilitation and return to work. After completing rehabilitation, approximately two thirds of the group had a lower stress level, although not significantly lower in terms of autonomous dysfunction compared to the time before the rehabilitation. All patients reported problems with bodily stress symptoms, primarily in the form of pain and lack of energy. The majority were found to be in the $51-75$ $\mathrm{p}$ interval with relatively mild symptoms. Overall, the results indicate a trend towards improvement, although not significant and the remaining stress symptoms were at a level where they may constitute an obstacle in everyday life and when returning to work.

Results of the SCI-93 questionnaire, rated by 16 patients after two weeks

All participants had experienced burden some events or periods in their life for example, traumatic experiences such as childhood abuse, serious illness as diabetes and other severe crises such as loss of a close relative. In addition, the ED meant a great crisis and a loss of identity.

After 14 weeks rehabilitation, most of them still had a strong feeling of illness and had for example obvious somatic symptoms of fibromyalgia and depression. Their belief in regaining health, function and ability was weak and they considered that returning to work was not currently an option. All of them acknowledged the need for sick leave at this point in time. Only one patient reported a realistic need for permanent sick leave. 


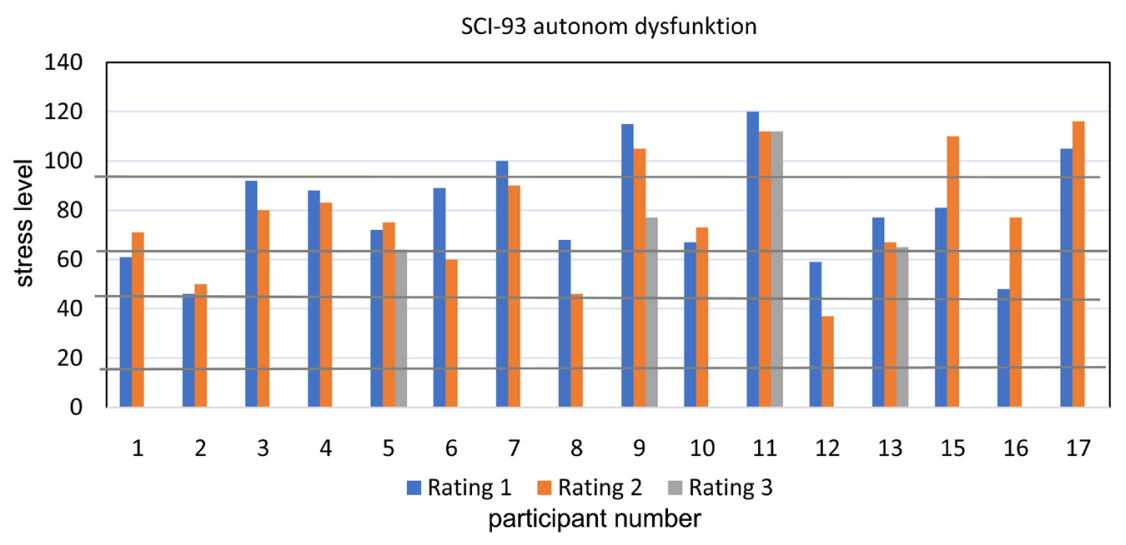

Figure 2. Rating of autonomous dysfunction. No. 14 dropped out.

\section{Results of the CRI, Coping Resources Inventory}

The test reflected the patients' cognitive, social, emotional, spiritual and physical coping ability. At the start of rehabilitation, all patients were positioned within the lower part of normal variation. It was only in a few patients that the curve indicated a slight improvement, although still within the lower part of normal variation, while the curve of just one patient indicated a clear improvement in terms of emotional coping ability.

\section{Discussion}

Patients with ED are in most cases affected by complex problems of a somatic as well as a psychological nature [6] and the group of patients in the present evaluation is no exception. All of them met the National Board of Health and Welfare [29] criteria for an ED diagnosis and were seriously ill before the start of the NBR. The profound and wide-ranging complex of problems involving long periods of sick leave can, in this evaluation, be considered to explain the lack of positive results in terms of return to work, as reported in some other Swedish studies [11]. However, the results from the follow-up interview 12 months after completed rehabilitation stated that the patients had managed to break the previous, negative spiral towards increasing illness and care consumption as well as preventing the risk of permanent sick leave.

Before the rehabilitation, the patients had received treatment generally available in Sweden today, i.e., sick leave, medication, rest and training to return to work, in accordance with the rehabilitation chain of the National Board of Health and Welfare [2]. A few patients had tested cognitive psychotherapy, today offered almost routinely by the healthcare service in Sweden without due consideration. The practice can be questioned with respect to that these patients often are suffering from cognitive impairment and the lack of evidence of effect. Cognitive psychotherapy that only focuses on changing thought patterns with the help of exercises, which are intended to modify behaviors, can instead lead to increased mental fatigue and in turn result in more stress and more failures [30]. It is also contrary to what has been stated by some researchers, that the patients 
need more individually adapted rehabilitation [8].

For most individuals who are diagnosed with ED, a period of sick leave is necessary, but long-term sick leave can also lead to secondary negative effects as well as the risk of developing an illness identity [31]. However, there were no tendencies towards an identity marked by illness in our investigated group. Most of the patients were characterized by their persistence, as well as their refusal to give up which sometimes may be seen as a strength and be used constructively in rehabilitation.

To spend time in a natural environment has been found to be beneficial for individuals affected by stress disorder [32]. Probably the greatest impact from the environment takes place on an unconscious level when several of our senses are stimulated in a positive way. Nature often can be experienced as beautiful and exciting; there are many different sounds and smells. Research on fractals in nature is interesting from the fact that the human is attracted to patterns from an early age [18]. When testing a three-month-old baby, you can see that the baby can already discriminate new patterns, prefers certain patterns, prefers new patterns and habituates to patterns, which means that the reaction decreases [33]. This is in line with the research on fractals which showed that, a visual pattern with little variation is not engaging enough to continue looking at [18]. With the baby, you can see that attention is enhanced by a little more complex pattern. Purely speculative, one might think that humans may be drawn to the type of natural environment in which one feels stimulated, but not overstimulated [34].

The patients in this evaluation appreciated the rehabilitation environment but were unable to find words to describe what and why it made them feel good. It appears as if the nature constituted a calming, facilitating environment and was an obvious, integrated part of the rehabilitation itself. Most likely, the patients perceived the rehabilitation as a whole and did not give much thought to which part in the rehabilitation was the most crucial. That is in line with the desire, how a multidisciplinary team should function "the whole is greater than the sum of its parts" [35].

The purpose of a multidisciplinary team is to avoid splitting up the patient's various symptoms and treatment. There must be no competition between the parts of the treatment this requires good collaboration between the team members that they jointly agree on the goals and sub-goals to be set for each individual patient. In addition to good professional knowledge and experience, a multidisciplinary team must be well established otherwise it can lead to disruption and insecurity for the patient. For a patient with a serious psychosomatic condition and with deep psychological problems it is a big challenge to provide successful treatment. It is therefore important to understand that unilateral medical care is not enough but nor are activities and stays in a natural environment. That is why NBR with a multidisciplinary team may be a suitable alternative for patients with ED. 
Trust is one of the foundations of healthcare [29]. The participants in the present study expressed great trust in the staff members' knowledge of ED. The experience "to be seen", taken seriously and be understood by the staff members was both new and surprising to many of the patients. This contrasted sharply with their earlier experiences of contacts with healthcare, the Swedish Social Insurance Agency [36], and in several cases even their relatives. A lack of understanding on the part of those around them can be related to the large variation in symptoms, which leaves room for different interpretations of the patient's behaviours and what is expressed. Although it can be difficult to understand how a previously active and capable person can change to such a great extent, becoming so fragile, unsociable, disorganized, lacking in concentration and forgetful. It is not clear either why the patients in the study were underdiagnosed in terms of other somatic diseases. Some patients at the beginning of the rehabilitation already knew that they suffered from IBS or depression, but they had experienced not being taken seriously. Others who had undergone an investigation for dementia had perceived it as unprofessional, which strengthened their view of a lack of understanding and of shortcomings in healthcare.

The present evaluation also contains statements indicating that the patients' sense of resignation and helplessness also had influenced those who were trying to help them, which may happen and is described by Schmidtbauer [37]. The clearest evidence of this was the young patient who was advised to apply for permanent sick leave by the Swedish Social Insurance Agency, [36] because of the perception that all resources had been exhausted. As already mentioned, one year after the rehabilitation this patient had terminated the sick leave and obtained a part-time job. This example highlights the importance of knowledge of ED among those whose task is to help the patient.

A comprehensive diagnostic examination is a prerequisite in order to formulate realistic rehabilitation goals for the individual. Personal characteristics, which are required to know in order to benefit from the rehabilitation, were not included in the assessment of the patients before the rehabilitation. Maybe a preparatory intervention might have been better rather than extending the rehabilitation for those patients who did not manage to participate fully from the start. The fact that some participants had an underlying disease that probably contributed to severe their ED was became clear one year later. This confirms the need for a more thorough in-depth examination of underlying diseases before rehabilitation and would probably have provided better conditions for rehabilitation.

It was found that the participants in the present study had adapted themselves to their surroundings and that their self-esteem was performance-based, which is considered to be characteristic of patients with ED [5]. Consequently, there is a risk that performance-based behaviour is regarded as entirely negative, but a performance-based behaviour need not necessarily be a bad thing. The linkage between self-esteem, perfectionism and ED has been described as complex, which means that it can be important to take an individual's self-esteem into account in the treatment of ED [38]. An insecure person with low self-esteem relies on per- 
formance, often leading to so-called maladaptive perfectionism, whereas a person who is secure and whose self-esteem is good will accept making mistakes, so-called adaptive perfectionism. Therefore, strengthening an individual's selfesteem should be an essential part of ED treatment.

All patients invariably described the group and its individual members as positive and surprising. Experiencing togetherness in the group, in-depth conversations and laughter were perceived as unburdening, leading to reduced feelings of guilt and shame as well as having a positive effect on self-image and self-esteem, which confirms the importance of being able to verbalize and share emotions [39]. In the present evaluation, the patients' narratives are in line with studies demonstrating that the strength of group therapy lies in encountering like-minded persons, where they experience not being alone in finding themselves in a specific life situation [9]. The group members first show compassion towards other members, after which they apply it to themselves [40]. The specific expression of compassion used by the therapist serves as a model that is first employed in relation to the other group members and later to oneself.

Basic body awareness was also highly valued by most participants. The staff noted that patients experienced greater acceptance as well as being stimulated due to learning new aspects about themselves and their body, which made them more open to new insights and ability to recognize the links between their own behaviour and ED. According to Antonovsky [41], this supports the importance of comprehendability for the ability to deal with a problem and the so-called salutogenic theory. Moreover, the importance of increased body awareness in ED has been confirmed by other studies [42] [43].

The use of assessment scales in evaluations has both advantages and disadvantages. The advantage is that it is possible to reach many informants for a study and to use such a method may be of help in the clinic as a support for the staff, who feel uncertainty in a particular field. The disadvantage is that the information you get is limited by the questions in the scales and due to the impossibility of asking follow-up questions. Furthermore, one does not see subtle signs of change, which was the reason why we decided to include the interview method and the staff members' weekly notes.

The assessment scales in this study showed no significant improvement in the health of the participants after the rehabilitation. An explanation may be the severe problems of the participants and the relatively short period of rehabilitation. However, the interviews testified a change to improved health after the rehabilitation. All participants stated that NBR started a process, which indicated a deeper change of identity. This had in turn improved their quality of life and their state of health as well as contributed setting realistic goals for the future. The emergence of a new identity and a more realistic self-image is regarded as one of the most important results of the rehabilitation. It can be added that returning to work requires not only a rehabilitation to health but also a functioning support from the social insurance office, employer or employment service, as mentioned [8]. 


\section{Summary}

This study confirms that ED is a complex condition, requiring careful diagnosis and individually tailored rehabilitation. The result of the study showed that NBR with a multidisciplinary team provides a rehabilitation, which leads to an experience of improved health and improved quality of life for patients with ED. Provided that ED has not become chronic and that the patient is not multi sick, this model of NBR may constitute a good alternative treatment, but further evaluation and research are strongly recommended.

\section{Limitations of the Study}

The limitation of this study is mainly that the number of participants is quite small. But it provides detailed and important information about the complexity behind ED and the need for accurate diagnosis and an assessment of the patient's resources for recovery. For some patients, 14 weeks of rehabilitation was far too short time to achieve any real change, but the process of worsening the illness had been stopped.

Furthermore, the assessment scales used in this study could not catch any changes to confirm the results in the interviews. This may have to do with the fact that rating scales often have difficulties detecting individual and subtle changes, which is due to the construction of scales. Individual and subtle changes can be more easily detected in interviews. This shows the importance of the right study design to be able to increase knowledge about ED and create opportunities for adequate rehabilitation. However, in this study the assessment scales constituted a certain benefit, the patients experienced them as positive because it helped them to some extent to put their symptoms into words.

\section{Conflicts of Interest}

The authors have no conflicts of interest to declare.

\section{Funding}

This work was supported by Skaraborg Institute for Research and Development, Regionens Hus, Stationsgatan 3, SE-54130 Skövde, Sweden and Eastern Health Board, Region Västra Götaland, SE-46280 Vänersborg, Sweden.

\section{References}

[1] World Health Organization [WHO] (2019) Burn-Out an "Occupational Phenomenon": International Classification of Diseases. https://www.who.int/mental_health/evidence/burn-out/en

[2] The National Board of Health and Welfare (2017) Burn-Out Syndrome. Insurance Medical Decision Support. https://roi.socialstyrelsen.se/fmb/utmattningssyndrom/546

[3] Maske, U., Riedel-Heller, S., Seiffert, I., Jacobi, F. and Hapke, U. (2016) Prevalence and Comorbidity of Self-Reported Diagnosis of Burnout Syndrome in the General Population-Results of the German Health Interview and Examination Survey for 
Adults. Psychiatrische Praxis, 43, 18-24. https://doi.org/10.1055/s-0034-1387201

[4] Canfield, J. (2005) Secondary Traumatization, Burnout, and Vicarious Traumatization. Smith College Studies in Social Work, 75, 81-101.

https://doi.org/10.1300/J497v75n02_06

[5] Poncet, M.C., Toullic, P., Papazian, L., Kentish-Barnes, N., Timsit, J.-F., Pochard, F., Chevret, S., Schlemmer, B. and Azoouly, E. (2007) Burnout Syndrome in Critical Care Nursing Staff. American Journal of Respiratory and Critical Care Medicine, 175, 698-704. https://doi.org/10.1164/rccm.200606-806OC

[6] Ahlborg, J.G., Bergenheim, A., Eriksson, M., Jivegård, L., Sundell, G., Svanberg, T., Svensson, M. and Bernhardsson, S. (2020) Nature-Based Rehabilitation for Patients with Longstanding Stress-Related Disorders-Updated Report. Sahlgrenska University Hospital, Gothenburg.

[7] Arvidsdotter, T., Kylén, S. and Bäck-Pettersson, S. (2019) Experiences of Living with Stress-Related Exhaustion Disorder and Participating in a Tailor-Made Antistress Program in Primary Care. Psychology, 10, 1463-1484.

https://doi.org/10.4236/psych.2019.1011096

[8] Ståhl, A.-C.F., Ståhl, C. and Smith, P. (2018) Longitudinal Association between Psychological Demands and Burnout for Employees Experiencing a High versus a Low Degree of Job Resources. BMC Public Health, 18, Article No. 915. https://doi.org/10.1186/s12889-018-5778-x

[9] Downes, C., Kieran, S. and Tiernan, B. (2019) "Now I Know I'm Not the Only One": A Group Therapy Approach for Adoptive Parents. Child Care in Practice, 1-9. https://doi.org/10.1080/13575279.2019.1664992

[10] Grahn, P. and Stigsdotter, U. (2010) The Relation between Perceived Sensory Dimensions of Urban Green Space and Stress Restoration. Landscape and Urban Planning, 94, 264-275. https://doi.org/10.1016/j.landurbplan.2009.10.012

[11] Sahlin, E., Ahlborg, G., Matuszczyk, J. and Grahn, P. (2014) Nature-Based Stress Management Course for Individuals at Risk of Adverse Health Effects from Work-Related Stress-Effects on Stress Related Symptoms, Workability and Sick Leave. International Journal of Environmental Research and Public Health, 11, 6586-6611. https://doi.org/10.3390/ijerph110606586

[12] Stigsdotter, U. and Grahn, P. (2011) Stressed Individuals' Preferences for Activities and Environmental Characteristics in Green Spaces. Urban Forestry \& Urban Greening, 10, 295-304. https://doi.org/10.1016/j.ufug.2011.07.001

[13] Adevi, A.A. and Lieberg, M. (2012) Stress Rehabilitation through Garden Therapy: A Caregiver Perspective on Factors Considered Most Essential to the Recovery Process. Urban Forestry \& Urban Greening, 11, 51-58. https://doi.org/10.1016/j.ufug.2011.09.007

[14] Kaplan, S. (1995) The Restorative Benefits of Nature: Toward an Integrative Framework. Journal of Environmental Psychology, 15, 169-182.

https://doi.org/10.1016/0272-4944(95)90001-2

[15] Ulrich, R.S., Simons, R.F., Losito, B.D., Fiorito, E., Miles, M.A. and Zelson, M. (1991) Stress Recovery during Exposure to Natural and Urban Environments. Journal of Environmental Psychology, 11, 201-230. https://doi.org/10.1016/S0272-4944(05)80184-7

[16] Wilson, E.O. (2017) Biophilia and the Conservation Ethic. In: Mysterud, I., Ed., Evolutionary Perspectives on Environmental Problems, Routledge, Washington DC, 263-272. https://doi.org/10.4324/9780203792650-18

[17] Joye, Y. and De Block, A. (2011) "Nature and I Are Two": A Critical Examination of 
the Biophilia Hypothesis. Environmental Values, 20, 189-215. https://doi.org/10.3197/096327111X12997574391724

[18] Hagerhall, C.M., Laike, T., Taylor, R.P., Küller, M., Küller, R. and Martin, T.P. (2008) Investigations of Human EEG Response to Viewing Fractal Patterns. Perception, 37, 1488-1494. https://doi.org/10.1068/p5918

[19] The Swedish Social Insurance (2014) Sick Leave in Mental Diagnoses. A Study of Sweden's Population 16-64 Years. Social Insurance Report 2014: 4.

http://www.forskasverige.se/wp-content/uploads/Sjukfranvaro-Psykiska-Diagnoser2014.pdf

[20] World Medical Association [WMA] (2013) Declaration of Helsinki-Ethical Principles for Medical Research Involving Human Subjects. World Medical Association, Ferney-Voltaire.

https://www.wma.net//policies-post/wma-declaration-of-helsinki-ethical-principles -for-medical-research-involving-human-subjects/

[21] The Swedish Research Council (2011) Good Research Practice. http://www.vr.se/etik/publikationerochriktlinjer.4.45a6e939122880e7d8e80001820.h tml

[22] The Ethical Review Board (2021) Ethical Approval. https://etikprovningsmyndigheten.se

[23] Bourgeault, I. (2013) The SAGE Handbook og Qualitative Methods in Health Research. SAGE Publications Ltd., London.

[24] Schmidt, C. (2004) The Analysis of Semi-Structured Interviews. In: Flick, U., von Kardoff, E. and Steinke, I., Eds., A Companion to Qualitative Research, Rowohlt Taschenbuch Verlag GmbH, Reinbek bei Hamburg, 253-259.

[25] DiCicco-Bloom, B. and Crabtree, B.F. (2006) The Qualitative Research Interview. Medical Education, 40, 314-321. https://doi.org/10.1111/j.1365-2929.2006.02418.x

[26] Braun, V. and Clarke, V. (2006) Using Thematic Analysis in Psychology. Qualitative Research in Psychology, 3, 77-101. https://doi.org/10.1191/1478088706qp063oa

[27] Nyström, K. and Nyström, O. (2019) Stress and Crisis Inventory, SCI-93. Medendus, Tranås.

[28] Marting, M.S. and Hammer, A.L. (2004) Coping Resources Inventory: Manual and Sampler Set. Mind Garden, Inc., Menlo Park.

[29] The National Board of Health and Welfare (2017) The Health Care Act, 2017:30. https://patientsakerhet.socialstyrelsen.se/om-patientsakerhet/centrala-lagar-och-for eskrifter/halso-och-sjukvardslagen

[30] Hofmann, S.G., Asnaani, A., Vonk, I.J., Sawyer, A.T. and Fang, A. (2012) The Efficacy of Cognitive Behavioral Therapy: A Review of Meta-Analyses. Cognitive Therapy and Research, 36, 427-440. https://doi.org/10.1007/s10608-012-9476-1

[31] Rutz Mittendorfer, E., Alexanderson, K., Kjeldgård, L. and Wikma, A. (2011) Sick Leave and Risk of Future Sickness and Activity Compensation among Women and Men. Sub-Report 3 in Projects on Women's and Men's Sick Leave. Karolinska institutet, Stockholm.

[32] Währborg, P., Petersson, I.F. and Grahn, P. (2014) Nature-Assisted Rehabilitation for Reactions to Severe Stress and/or Depression in a Rehabilitation Garden: Long-Term Follow-Up Including Comparisons with a Matched Population-Based Reference Cohort. Journal of Rehabilitation Medicine, 46, 271-276.

https://doi.org/10.2340/16501977-1259

[33] Albers, C.A. and Grieve, A.J. (2007) Bayley Scales of Infant and Toddler Develop- 
ment-Third Edition. San Antonio, TX: Harcourt Assessment. Journal of Psychoeducational Assessment, 25, 180-190. https://doi.org/10.1177/0734282906297199

[34] Mandelbrot, B.B. (1983) The Fractal Geometry of Nature. WH Freeman and Co., New York.

[35] Thylefors, I., Persson, O. and Hellström, D. (2005) Team Types, Perceived Efficiency and Team Climate in Swedish Cross-Professional Teamwork. Journal of Interprofessional Care, 19, 102-114. https://doi.org/10.1080/13561820400024159

[36] The Swedish Social Insurance Agency (2021) Information on Sickness Benefit. https://www.forsakringskassan.se/english

[37] Schmidbauer, W. (2018) The Helpless Helpers: About the Emotional Problems of the Helping Professions. Rowohlt Verlag GmbH, Reinbek.

[38] Makower, I. (2018) Self-Esteem and Perfectionism: Theory, Research and Clinical Application. Studentlitteratur, Lund.

[39] Monsen, J.T., Eilertsen, D.E., Melgård, T. and Ødegård, P. (1996) Affects and Affect Consciousness: Initial Experiences with the Assessment of Affect Integration. The Journal of Psychotherapy Practice and Research, 5, 238-249. https://doi.org/10.1037/t51464-000

[40] Viou, M. and Georgaca, E. (2019) Compassionate Voices of Clients and Therapists in Systemic Group Psychotherapy: A Narrative Study. Journal of Constructivist Psychology, 33, 422-440. https://doi.org/10.1080/10720537.2019.1679302

[41] Antonovsky, A. (1987) Unraveling the Mystery of Health: How People Manage Stress and Stay Well. Jossey-Bass, San Francisco.

[42] Kabat-Zinn, J. and Hanh, T.N. (2009) Full Catastrophe Living: Using the Wisdom of Your Body and Mind to Face Stress, Pain, and Illness. APPENDIX A, the Foundation of Mindfulness Practice: Attitudes \& Commitment. The American Psychological Association, Washington DC.

[43] Landsman-Dijkstra, J.J., van Wijck, R. and Groothoff, J.W. (2006) Improvement of Balance between Work Stress and Recovery after a Body Awareness Program for Chronic a Specific Psychosomatic Symptoms. Patient Education and Counseling, 60, 125-135. https://doi.org/10.1016/j.pec.2004.12.004 